1 London School of Hygiene and Tropical Medicine, Centre on Climate Change and Planetary Health, Pathfinder Initiative, London, UK

2 School of Biological Sciences, University of East Anglia, UK

3 Sea4Us, Biotecnologia e Recursos Marinhos, Portugal

4 London, UK

Correspondence to: P Murage: Peninah.Murage@lshtm.ac.uk Cite this as: BMJ 2021;375:n2329 http://dx.doi.org/10.1136/bmj.n2329 Published: 5 October 2021

\section{From drug discovery to coronaviruses: why restoring natural habitats is good for human health}

Peninah Murage and colleagues argue that biodiversity is the cornerstone of healthy natural habitats. Its preservation is vital to human health and should therefore be embedded into medical and healthcare studies

\section{Peninah Murage, ${ }^{1}$ Helena Reis Batalha, ${ }^{2}$ Silvia Lino, ${ }^{3}$ Kamil Sterniczuk ${ }^{4}$}

The restoration and protection of natural habitats enhance biological diversity (biodiversity; box 1). These two concepts (natural habitats and biodiversity) are interdependent because complex symbiotic interspecies relationships are the foundation of thriving natural habitats. Nearly every aspect of our survival depends on exploiting natural resources-when land is converted for food production and housing, for example, or for the extraction of energy, raw materials, and water. The unsustainable use of natural resources has led to short term improvements in human health characterised by increases in life expectancy and a global decline in poverty. ${ }^{1}$ But these are matched by an unprecedented alteration of the natural world characterised by loss of primary forests, species extinction, concentration of greenhouse gases, and ocean acidification, among others. ${ }^{1}$ This has perilous consequences to the planet and to human health in the long term.

Box 1: Biodiversity and ecosystems

The Convention on Biological Diversity defines biological diversity (biodiversity) as the variability among living organisms from all sources (including terrestrial, marine, and other aquatic ecosystems) and the ecological complexes of which they are part. This includes diversity within species, between species, and of ecosystems. Ecosystem means a dynamic complex of plant, animal, environment interacting as a functional unit. Habitat means the place or type of site where an organism or population naturally occurs.

Biodiversity should be preserved at three levels: ecosystem, species, and genetic. In other words, we should preserve a diversity of ecosystems on Earth, and within those ecosystems we should preserve a diversity of species, as the more biodiverse ecosystems are resilient to change. Genetic diversity within a species refers to all the genes and alleles contained in the individuals of that species. It serves as a reservoir of development possibilities, and it can help species adapt to future environment changes.

A study looking at the distribution of the global biomass (total weight of organisms) gives a sobering account of our effect on species diversity. ${ }^{2}$ It shows how humans and livestock have dominated the mammalian biomass and substantially altered the species balance leading to a major loss of plants, a sevenfold loss of large land mammals, and a fivefold decrease in marine mammals. This is despite humans accounting for a rather insignificant $0.01 \%$ of the total species biomass (fig 1). Humans and livestock and make up $96 \%$ of all mammalian biomass (fig 1) ${ }^{2}$; a phenomenal imbalance in the mammalian species that could be attributed to agriculture and food production. and micro-organism communities and their non-living outweigh all vertebrates combined (except for fish) 

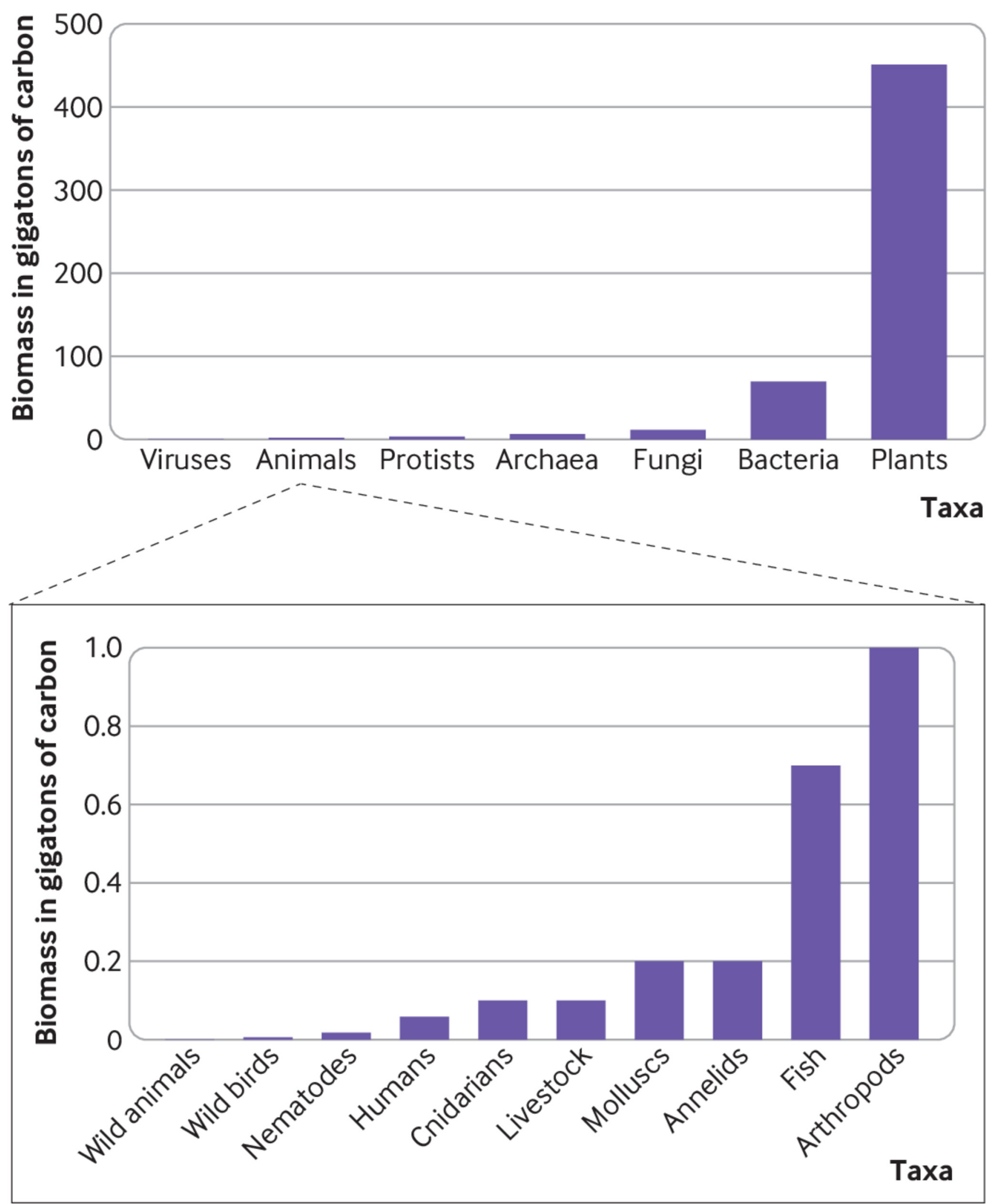

Fig 1 | Global biomass by biological classification showing the relative distribution of the $\sim 550$ gigatons of carbon (GtC) of biomass. Data reproduced with permission ${ }^{2}$

Species dominance disrupts the functioning of ecosystems by endangering ecosystem services, or the countless benefits that the natural environment provides us free of charge. ${ }^{3}$ The Millennium
Ecosystem Assessment provides a framework for understanding the complex links between these ecosystems services and human health by broadly categorising the services as provision of resources, 
regulating the environment, providing recreational spaces, and supporting ecosystem functioning through, for example, soil formation and nutrient cycling. ${ }^{3}$

In this paper we discuss the role of four ecosystem services (drug discovery, regulation of zoonotic diseases, food provision, and supporting wellbeing) in revolutionising medicine and the population health consequences of their imminent decline. We describe how contact with nature is increasingly sought to manage and treat physical and mental conditions through green prescriptions and argue that medical and health education curriculums should be overhauled to incorporate ecological considerations.

\section{Biodiversity and drug discovery}

Biodiverse ecosystems have been the source of numerous pharmaceutical compounds over millennia. Drug discovery currently includes sourcing natural bioactive molecules from land and marine based plants, animals, and microorganisms. These original molecules often serve as inspiration for synthetic ones that are later produced as components for new drugs.

Some notable land based examples include penicillin, an antibiotic that was originally sourced from the fungi Penicillium spp; aspirin, derived from a compound originally extracted from the bark of the willow trees Salix alba ${ }^{4}$; paclitaxel, a chemotherapy drug originally extracted from the Pacific yew tree Taxus brevifolia, which is now endangered ${ }^{5}$; and tacrolimus, an immunosuppressant drug used in organ transplants to prevent rejection, discovered from soil samples that contained the bacteria Streptomyces tsukubaensis. ${ }^{6}$

Marine natural products also show an interesting array of diverse and novel chemical structures with potent biological activities. Many agents derived from marine organisms are currently in various stages of preclinical development for a broad range of potential applications. Examples of currently used marine derived drugs include: antibiotics from marine fungus (cephalosporins); compounds isolated from marine sponges used in cancer treatment (eribulin and cytarabine) and to treat viral infections such as herpes (vidarabine); and a neurotoxin isolated from a marine snail with painkiller properties that make it 10 ooo times more potent than morphine and without the side effects (ziconotide).

Marine habitats rich in species are likely to hold many more compounds that could be used to treat debilitating diseases and alleviate pressures on health systems. Ocean acidification, which occurs when carbon dioxide emissions dissolve in oceans, ${ }^{7}$ poses a major threat to many marine biomes and species, risking a permanent loss of reservoirs of potential molecules. The genetic diversity in biodiverse habitats makes them more resilient to changes such as climate variability, although the climate extremes predicted pose major challenges to the adaptive capacity of even the most resilient habitats.

\section{Pandemics, zoonotic diseases, and biodiversity loss}

An estimated $75 \%$ of all emerging infectious diseases in humans have a zoonotic origin, ${ }^{8}$ meaning they are caused by pathogens from animal hosts. These diseases are a major challenge to human health, commonly resulting in endemic diseases (leptospirosis, helminthiases, Lyme and hantavirus diseases) and sometimes resulting in epidemics, such as Ebola and HIV/AIDS, ${ }^{8} 9$ and pandemics, such as covid-19 (box 2). The spread of zoonotic diseases also threatens economies; the true economic cost of covid-19 is incalculable, but early estimates indicate that the cumulative financial costs could amount to $\$ 16 \mathrm{tn}$ ( $€ 12 \mathrm{tn}$; $€ 14 \mathrm{tn}) .^{12}$

\section{Box 2: Emerging zoonotic diseases and coronaviruses}

The United Nations environment programme's Frontiers report in 2016 defined emerging zoonotic diseases as those that newly appear in a population or have existed previously but are now rapidly increasing in incidence or geographical range. ${ }^{8}$ Coronaviruses are a family of viruses that cause respiratory and intestinal infections in animals and humans. ${ }^{10}$ They include SARS-CoV and MERS-CoV viruses, which were responsible for the outbreaks of SARS (severe acute respiratory syndrome) and MERS (Middle East respiratory syndrome), respectively, ${ }^{10}$ and more recently SARS-CoV-2, which is responsible for the covid-19 pandemic. Although the primary source of SARS-CoV-2 has not been identified, the virus shares up to $90 \%$ genetic similarities with other viruses that have been found in horseshoe bats and pangolins. ${ }^{11}$

The role of biodiversity in animal-to-human transmission has been contested: on the one hand, biodiversity has been traditionally seen as a source of new pathogens, ${ }^{11}$ but in other circumstances it can decrease the transmission of zoonotic diseases that have already become established in humans through the "dilution effect," by which biodiversity regulates the populations of susceptible hosts and decreases the abundance of parasites. ${ }^{13}$

The view that species rich environments can serve as sources for new pathogens-thereby supporting higher rates of animal-to-human transmission and the emergence of new disease-would mean that biodiversity is a hazard to human health. ${ }^{11}$ But emerging evidence shows that some animal species, such as domesticated animals, primates, rodents, and bats, are far more likely to be zoonotic hosts than others. ${ }^{11} 14$ Increases in abundance of these populations is responsible for a much higher rate of virus spillover. ${ }^{11} 14$ In short, the next emerging infectious disease is far more likely to come from a rat than a rhino. ${ }^{15}$ As we transform natural habitats to croplands, grazing lands, and cities, we inadvertently increase domesticated and fast lived species, which thrive in these altered environments and are more likely to harbour pathogens transmissible to humans. ${ }^{15}$ In other words, altering natural habitats increases the probability of transmission of zoonotic infectious diseases ${ }^{15}$

\section{Food security and nutrition}

Approximately $43 \%$ of the earth's land surface is currently used for food production. ${ }^{16}$ Sustaining sufficient nutritious food for everyone (food security) without placing pressure on natural resources is a phenomenal feat. The environmental effects of producing food for over 7.8 billion people are staggering and include degraded land and aquatic ecosystems, depletion of water sources, and climate change (an estimated $27 \%$ of anthropogenic greenhouse gas emissions can be attributed to the food supply chain). ${ }^{16}$

Biodiversity is indispensable to food security and nutrition and vital for sustainable food production. ${ }^{17}$ Attempts to maximise food production through pesticides and fertilisers disrupt ecosystem regulating services such as insect pollination and profoundly affect food security by reducing the yield derived from pollinator dependent crops. ${ }^{18}$ The full loss of natural pollinators would lead to a $22.9 \%$ decline in global fruit supplies, $16.3 \%$ decline in vegetables, and $22.1 \%$ decline in nuts and seeds, leading to an estimated 1.42 million annual deaths from non-communicable diseases and malnutrition related diseases globally. ${ }^{19}$

Soil is the foundation of food production and nutrition; it is a vital yet underrated biodiverse ecosystem. Soil is home to interacting communities of microorganisms, fungi, and invertebrates that contribute to soil health and nutrient richness, thereby nourishing plants and supporting all life on earth. Soil ecosystem services such 
as soil formation and nutrient cycling are foundational to all other ecosystem services-without soil, almost all other ecosystem services would fail to function. ${ }^{2}$ The health effects of declining soil ecosystem services occur over very long periods of time, which might explain the lack of empirical evidence. ${ }^{3}$

Loss of marine ecosystems also has major implications for food security, nutrition, and livelihood. Unsustainable fish farming threatens marine ecosystems such as mangrove forests, which are vital habitats for fish populations, ${ }^{20}$ and has implications for the many coastal communities who depend on fish as a source of protein and for livelihood. In addition to nutritional and economic effects, declining fish populations disrupt marine food webs resulting in ecological imbalances, with knock-on effects on other coastal habitats such as coral reefs. ${ }^{17}$

\section{Health and wellbeing}

Access to nature promotes healthy lifestyles such as walking, cycling, and sports. This in turn helps prevent cardiovascular diseases, diabetes, and some cancers by lowering blood pressure and cortisol levels ${ }^{2122}$ and by enhancing immune system function. ${ }^{22}$ Access to nature also benefits mental health and has been shown to reduce anxiety, improve mood, and boost self-esteem. ${ }^{21}$ These health benefits have made a case for nature prescribing as a complementary therapy for managing mental and physical illness. In England, a national initiative spearheaded by the Department for Environment, Food, and Rural Affairs and NHS England has been awarded $€ 5.77 \mathrm{~m}$ to develop ways of scaling up green social prescribing. ${ }^{23}$

The natural environment also encourages community cohesion, which has been associated with lower crime rates in urban areas. ${ }^{24}$ Greenspaces in urban settings also provide critical regulatory services that minimise environmental risks associated with poor health, such as air quality, flooding, and exposure to heatwaves. ${ }^{21}$ Evidence shows that biodiverse urban ecosystems characterised by multiple species and multiple layers of trees and shrubs offer more effective cooling of urban environments than single layered single trees species. ${ }^{25}$

Before we can achieve the full potential of nature's effects on human health, we must tackle the existing inequities in access, allocation, and management of natural resources. Inequality in access is a barrier to realising health benefits when the most deprived and marginalised groups have the least access to urban greenspaces. ${ }^{21}$ Likewise, rapid loss of natural habitats and environmental degradation disproportionately affect indigenous communities who rely on these habitats for livelihood.

\section{Nature based solutions}

Human health is fundamentally dependent on healthy biodiverse ecosystems. Unfortunately, the prosperity of our species is matched by declining natural systems. Our debt to nature is vast; the global cost of the ecosystem services provided by natural crop pollinators is $\$ 195 \mathrm{bn}-\$ 657 \mathrm{bn}^{26}$ and the use of penicillin and other antibiotics is estimated to have extended the average human lifespan by 23 years. ${ }^{27}$ The covid-19 pandemic is a reminder that our exploitation of nature might be reaching a tipping point.

The enormous challenge we now face is safeguarding population health and meeting development goals within the safe limits of existing natural systems. Achieving this will require transformational changes in nearly every aspect of society. Nature based solutions are a viable means of restoring natural habitats without compromising human health and prosperity (box 3). They have gathered momentum over the years because of their potential to enhance the natural environment while tackling multiple societal challenges. $^{28}$

\section{Box 3: Types of nature based solutions and their effects on human health}

Nature based solutions can be grouped by the degree of intervention involved. ${ }^{28}$ Type 1 involves minimal intervention, such as keeping wetlands intact to restore habitats, sustain food supplies, and reduce risk of flooding. Type 2 includes moderate interventions, such as integrating trees and shrubs in cropland (agroforestry) to prevent soil erosion, improve water catchment, and increase crop yields, which has nutritional, economic, and carbon sequestration benefits. Type 3 is much more intrusive and might involve creating new ecosystems in urban areas such as installing green roofs to provide cooling, reduce heat exposure, improve air quality, and, if implemented at scale, these interventions can also sequester carbon.

In food production, proposed solutions include a wide range of sustainable intensification agricultural techniques that maximise productivity while taking environmental effects into account. ${ }^{17}$ One technique is diversification, which entails the intentional integration of crop, livestock, forest, and aquatic resources to deliver multiple socioeconomic and biodiversity benefits. ${ }^{17}$ When properly implemented, diversification supports positive interactions between species and minimises the environmental effects of food production. Examples include using livestock to provide manure for crop fertilisation and using trees and shrubs to provide improved nutrient cycling and nitrogen fixation, which reduces the use of fertilisers. ${ }^{17}$ The climate mitigation potential of integrating trees in croplands is now widely acknowledged, ${ }^{29}$ as are the climate resilience benefits through increased crop yields and income for climate vulnerable populations. ${ }^{17}$

The sustainable management of wetlands and aquatic systems is also key to restoring biodiversity, improving livelihoods, and reversing climate change. Mangrove restoration efforts improve the productivity of fisheries, enhance coastal safety by offering protection from flooding and tsunamis, and sequester carbon from the atmosphere. ${ }^{20}$ Likewise, in marine systems, biodiversity conservation actions that promote intact ecosystems and increase species abundance are vital in mitigating the effects of ocean acidification and promoting climate change resilience. ${ }^{7}$ In urban areas, green infrastructure is increasingly used to build resilience against heatwaves and flooding, with many biodiversity benefits. Green roofs in densely populated cities offer transformative solutions that show the potential to co-exist with nature even in limited spaces. Some of the largest urban green roofs span hundreds of acres, ${ }^{30}$ with many discernible benefits including urban cooling, pollution reduction, and protection of wildlife species that would otherwise not thrive in the harsh urban environments. Species diversity is at the very heart of implementing nature based solutions. ${ }^{28}$ Approaches that encourage species dominance such as large scale single species tree planting (monoculture) do not fit the criteria for nature based solutions as they result in ecosystem collapse and the loss of ecosystem services that support human wellbeing.

Working with nature to solve societal challenges will also require reimagining our cross-discipline relations. The covid-19 pandemic has created an opportunity to unify health, economics, and environmental objectives, but only radical and transformational thinking will keep the momentum going. Part of this will include a curriculum overhaul to integrate "threshold concepts" from biodiversity and ecology into medicine, nursing, public health, economics, and development studies. Current public health models, though credited for advancing population health (through 
vaccination programmes and improved sanitation, for example), are ill equipped to tackle the problems that we face in the Anthropocene era. ${ }^{31}$ To paraphrase Albert Einstein, "No problem can be solved using the same thinking that created it." Human population growth is a public health success story, but, when uncontrolled, it is devastating for the environment; planetary health presents an alternative and promising approach by reminding us of our interconnectedness with nature and by blurring the artificial disciplinary boundaries that limit cross disciplinary collaborations. Fields such as environmental epidemiology and disease ecology are pioneering cross disciplinary work.

Health professionals can build on the tremendous success of public health to deliver the ambitions set by planetary health and propel us to a future where we co-exist harmoniously with nature. This can be achieved by championing behaviour changes that promote human health and reduce negative environmental effects, such as "planetary healthy diets," characterised by less meat and more fruits, vegetables, and whole grains, and active travel to combat obesity, reduce carbon emissions, and improve air quality.

\section{Key messages}

- Biological diversity supports the health of ecosystems and is a cornerstone to thriving natural habitats

- Ecosystem destruction significantly challenges human health in terms of drug discovery, zoonotic diseases, food security and nutrition, and health and wellbeing

- Nature based solutions can achieve multiple health and environmental objectives, thereby benefiting humans and nature, but successful implementation requires cross disciplinary efforts

- We need a curriculum overhaul to incorporate the teaching of biodiversity and ecology in medicine, nursing, public health and other related studies

Contributors and sources: PM is the guarantor. She is an environmental epidemiologist examining the health effects of environment changes, the interdependencies between people and natural systems, and solutions to promote health, safeguard ecosystems, and achieve sustainable development. HB is a biology teacher at foundation year level at the University of East Anglia. She has a background in conservation genetics and ecology and has worked with the endangered and endemic bird Cape Verdean warbler. SL is a research scientist and project manager at Sea4Us Portugal, a marine biotechnology company that surveys marine communities for potential pharmaceutical drugs. Her PhD in marine biology looked at potential therapeutic applications of deep sea marine animal lipids. KS is a patient who uses his long experience to help medical research. He is active in various National Institute of Health Research patient involvement panels. He also writes prolifically to champion patients' participation in research.

Patient involvement: Our patient co-author KS contributed to drafting various parts of the manuscript We are grateful for his account of experience with medical care and how contact with the natural world shaped his childhood and continues to offer him an antidote. This contributed to our discussion on how nature inspires drug discovery and health and wellbeing.

Competing interests: We have read and understood BMJ policy on declaration of interests and have the following interests to declare. SL is employed by Sea4Us, a biotechnology company in marine pharmaceutical research. The other authors have nothing to declare.

Whitmee S, Haines A, Beyrer C, etal. Safeguarding human health in the Anthropocene epoch: report of The Rockefeller Foundation-Lancet Commission on planetary health. Lancet 2015;386:1973-2028. doi: 10.1016/S0140-6736(15)60901-1 pmid: 26188744

2 Bar-On YM, Phillips R, Milo R. The biomass distribution on Earth. Proc Natl Acad Sci U S A 2018;115:6506-11. doi: 10.1073/pnas.1711842115 pmid: 29784790

3 Millennium Ecosystem Assessment. Ecosystems and human well-being: synthesis. 2005 https://www.millenniumassessment.org/documents/document.356.aspx.pdf

4 Desborough MJR, Keeling DM. The aspirin story-from willow to wonder drug. Br J Haematol 2017;177:674-83. doi: 10.1111/bjh.14520 pmid: 28106908

5 Mayor S. Tree that provides paclitaxel is put on list of endangered species. BMJ2011;343:d7411. doi: 10.1136/bmj.d7411 pmid: 22089836

6 Tanaka H, Nakahara K, Hatanaka H, Inamura N, Kuroda A. [Discovery and development of a novel immunosuppressant, tacrolimus hydrate]. Yakugaku Zasshi 1997:117:542-54 doi: 10.1248/yakushi1947.117.8_542 pmid: 9306728
7 Rastelli E, Petani B, Corinaldesi C, etal. A high biodiversity mitigates the impact of ocean acidification on hard-bottom ecosystems. Sci Rep 2020;10:2948.

doi: 10.1038/s41598-020-59886-4 pmid: 32076065

$8 \quad$ United Nations Environment Programme. Frontiers 2016: emerging issues of environmental concern. https://www.unep.org/resources/frontiers-2016-emerging-issues-environmental-concern

9 Gibb R, Franklinos LHV, Redding DW, Jones KE. Ecosystem perspectives are needed to manage zoonotic risks in a changing climate. BM/2020;371:m3389. doi: 10.1136/bmj.m3389 pmid: 33187958

10 Cui J, Li F, Shi Z-L. Origin and evolution of pathogenic coronaviruses. Nat Rev Microbiol 2019;17:181-92. doi: 10.1038/s41579-018-0118-9 pmid: 30531947

11 Keesing F, Ostfeld RS. Impacts of biodiversity and biodiversity loss on zoonotic diseases. Proc Natl Acad Sci USA 2021;118:1-8. doi: 10.1073/pnas.2023540118 pmid: 33820825

12 Cutler DM, Summers LH. The covid-19 pandemic and the \$16 trillion virus. JAMA2020;324:1495-6 doi: 10.1001/jama.2020.19759 pmid: 33044484

13 Civitello DJ, Cohen J, Fatima H, etal. Biodiversity inhibits parasites: broad evidence for the dilution effect. Proc Natl Acad Sci USA2015;112:8667-71. doi: 10.1073/pnas.1506279112 pmid: 26069208

14 Gibb R, Redding DW, Chin KQ, etal. Zoonotic host diversity increases in human-dominated ecosystems. Nature 2020;584:398-402. doi: 10.1038/s41586-020-2562-8 pmid: 32759999

15 Ostfeld RS, Keesing F. Species that can make us ill thrive in human habitats. Nature 2020;584:346-7. doi: 10.1038/d41586-020-02189-5 pmid: 32760034

16 Poore J, Nemecek T. Reducing food's environmental impacts through producers and consumers. Science 2018;360:987-92. doi: 10.1126/science.aaq0216 pmid: 29853680

17 Food and Agriculture Organisation of the United Nations. The state of the world's biodiversity for food and agriculture. 2019. http://www.fao.org/3/CA3129EN/CA3129EN.pdf

18 Crenna E, Sala S, Polce C, Collina E. Pollinators in life cycle assessment: towards a framework for impact assessment. J Clean Prod 2017;140:525-36doi: 10.1016/j.jclepro.2016.02.058.

19 Smith MR, Singh GM, Mozaffarian D, Myers SS. Effects of decreases of animal pollinators on human nutrition and global health: a modelling analysis. Lancet 2015;386:1964-72. doi: 10.1016/S0140-6736(15)61085-6 pmid: 26188748

20 Bosma RH, Debrot AO, Rejeki S, et al. Associated mangrove aquaculture farms. Building with nature to restore eroding tropical muddy coasts. (Ecoshape technical report no 4). Dordrecht, 2020. https://edepot.wur.nl/534041

21 WHO Regional Office for Europe. Urban green space interventions and health: a review of impacts and effectiveness. 2017. https://www.euro.who.int/en/health-topics/environment-andhealth/Climate-change/publications/2017/urban-green-space-interventions-and-health-a-reviewof-impacts-and-effectiveness.-full-report-2017

22 Twohig-Bennett $\mathrm{C}$, Jones $\mathrm{A}$. The health benefits of the great outdoors: a systematic review and meta-analysis of greenspace exposure and health outcomes. Environ Res 2018;166:628-37. doi: 10.1016/j.envres.2018.06.030 pmid: 29982151

23 NHS England. Green social prescribing. 2020. https://www.england.nhs.uk/personalisedcare/socialprescribing/green-social-prescribing

24 Weinstein N, Balmford A, DeHaan CR, Gladwell V, Bradbury RB, Amano T. Seeing community for the trees: the links among contact with natural environments, community cohesion, and crime Bioscience 2015;65:1141-53doi: 10.1093/biosci/biv151.

25 Park J, Kim J-H, Lee DK, Park CY, Jeong SG. The influence of small green space type and structure at the street level on urban heat island mitigation. Urban For Urban Green 2017:21:203-12doi: 10.1016/j.ufug.2016.12.005

26 Porto RG, de Almeida RF, Cruz-Neto O, etal. Pollination ecosystem services: A comprehensive review of economic values, research funding and policy actions. Food Secur 2020;12:1425-42doi: 10.1007/s12571-020-01043-w.

27 Hutchings MI, Truman AW, Wilkinson B. Antibiotics: past, present and future. Curr Opin Microbiol 2019;51:72-80. doi: 10.1016/j.mib.2019.10.008 pmid: 31733401

28 Cohen-Shacham E, Walters G, Janzen C, Maginnis S. Nature-based solutions to address global societal challenges. Aug 2016. https://portals.iucn.org/library/node/46191

29 Griscom BW, Adams I, Ellis PW, etal. Natural climate solutions. Proc Natl Acad Sci USA 2017;114:11645-50. doi: 10.1073/pnas.1710465114 pmid: 29078344

30 Greater London Authority. Living roofs and walls from policy to practice. 10 years of urban greening in London and beyond. 2019. https://livingroofs.org/london-2019-green-roof-report/

31 Rayner G. Conventional and ecological public health. Public Health 2009:123:587-91 doi: 10.1016/j.puhe.2009.07.012 pmid: 19748106

This article is made freely available for use in accordance with BMJ's website terms and conditions for the duration of the covid-19 pandemic or until otherwise determined by BMJ. You may use, download and print the article for any lawful, non-commercial purpose (including text and data mining) provided that all copyright notices and trade marks are retained. 